EGTRIB Journal

JOURNAL OF

THE EGYPTIAN SOCIETY OF TRIBOLOGY

VOLUME 19, No. 1, January 2022, pp. 66-82 ISSN 2090 - 5882

(Received December 27. 2021, Accepted in final form December 29. 2021)

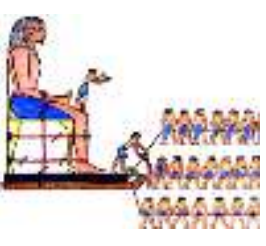

\title{
PERFORMANCE EVALUATION OF APRICOT KERNEL OIL-BASED CUTTING-FLUID USING L27 ORTHOGONAL ARRAYS DESIGN
}

\author{
Ossia C.V. and Big-Alabo, A. \\ Applied Mechanics \& Design (AMD) Group, Mechanical Engineering Department, \\ University of Port Harcourt, Port Harcourt, Nigeria.
}

\begin{abstract}
This study presents the performance evaluation of Apricot (Prunus armeniaca L.) kernel oil vegetable-based cutting fluid (AKO VBCF) using L27 orthogonal arrays design in the turning of AISI 1020 steel. The evaluation criteria were surface roughness $\left(X_{S R}\right)$, surface temperature $\left(X_{S T}\right)$, and chip thickness $\left(X_{C T}\right)$ based on cutting speed $\left(X_{s}\right)$, cutting time $\left(X_{t}\right)$, and cutting depth $\left(X_{d}\right)$ variables. The results showed that the turning performances were greatly influenced by $X_{s}$. All process variables showed positive main effects on $X_{S T}$, in the order $X_{s}>X_{d}>X_{t}$ for AKO VBCF, but the reverse order for hydrocarbon-basedcutting fluid (HBCF). Rotating speed, $X_{s}$ showed higher negative main effect on $X_{S R}$, followed by $X_{t} . X_{d}$ main effect was positive for both cutting fluids. AKO VBCF $X_{s}$ main effect was greater than that of HBCF. There was no interaction effect in HBCF unlike AKO VBCF with negative $X_{s} X_{t}$ and positive $X_{s} X_{d}$ interaction. For both cutting fluids $X_{C T}$ was independent of $X_{t}$. AKO VBCF showed negative quadratic effect of $X_{s}$, unlike HBCF which was positive. Finally, the second order multivariate models of $X_{S R}, X_{S T}$ and $X_{C T}$ showed close agreement between the predicted and experimental values.
\end{abstract}

\section{KEYWORDS}

Vegetable-based cutting fluids (VBCF), apricot kernel oil, lubricity, response surface methodology, orthogonal arrays.

\section{INTRODUCTION}

The threats by petroleum hydrocarbon based cutting fluid on the health of workers and the environment has spurred researches on environmentally friendly vegetable-based cutting fluids (VBCFs). Eziwhuo et al, [1], on the evaluation of Apricot Kernel, Avocado and African Pear Seed Oils as VBCF candidates in the Turning of AISI 1020 Steel showed that Apricot oil has the best VBCF potential. Anshika et al, [2], investigated the pharmacological benefits of Apricot oil extracted from wild apricot kernels and affirmed that the oil is low in acid value, rich in vitamin $E$, and rich in fatty acid, and thus useful for the development of massage cream. This confirms that Apricot is useful, healthy, and eco-friendly oil. There are different methods of oil extraction from plant seed (kernel) such as cold-pressing and solvent (Hexane) extraction. The procedure adopted by Gupta and Sharma, [3], is based on the cold-pressing and was shown to be better than the solvent extraction method. In extracting Apricot kernel oil and evaluating the raw-oil yield from dry matter utilizing the cold-pressing procedure of Gupta and Sharma [3], Kaya et al, [4], reported 48 - 50 \% (vol.) yield of raw-oil of total dry matter, while Kate et al, [5], 
presented $38-45 \%$ raw-oil matter. The extracted raw oil contains fatty acid components that can enhance the lubricity properties of cutting fluids at the cutting interface.

Several researchers (Femenia et el, [6], Ozkal et al, [7], Kaya et al, [4], and Gupta et al, [8]) have shown that apricot kernel oil consists of both unsaturated and saturated fatty acids. Femenia et al, [6], reported that unsaturated fatty acids (Oleic and linoleic acid) were approximately $92 \%$. Ozkal et al, [7], indicated that the fatty acid compositions of the apricot kernel obtained by hexane solvent showed $5.22-5.71 \%$ palmitic acid, 0.6 $0.78 \%$ palmitoleic acid, 1.0 - $1.30 \%$ stearic acid, 68.07 - $67.37 \%$ oleic acid, 25.11-24.81\% linoleic acid. Kaya et al, [4], showed that apricot kernel oil consisted of $93 \%$ unsaturated fatty acids (75 \% oleic acid, $17.5 \%$ linoleic acid), and saturated fatty acids $6.5 \%(4.5 \%$ palmitic acid and $2 \%$ stearic acid). Gupta et al, [8], reported 62.07 - $70.7 \%$ oleic acid, $20.5-27.76 \%$ linoleic, $0.4-1.42 \%$ linolenic for unsaturated fatty acids and palmitic acid $(5.0-7.79 \%)$ and palmitoleic acid $(0.48-0.70 \%)$ for the saturated fatty acids.

However, there are some researches on the use of VBCFs in drilling and / or turning operations that have adopted cutting parameters such as feed rates, cutting speed, depth of cut and other related parameters. Kuram et al, [9], studied the performances of 5 VBCFs with L9 orthogonal array experimental design, and the focus of the investigation was the thrust force and surface roughness in the drilling of AISI-304 using HSS-E tool. The machining parameters considered were sliding speed, feed rate and drill depth. The regression analysis showed that feed rate had greater effect on thrust force and surface roughness. The study showed that increase in feed rate result in a significant increase in the thrust force and surface roughness. Further observation showed that the sliding speed and drill depth had small and no significant influence respectively on thrust force and surface roughness with no tool wear on the application of all the cutting fluids. Onuoha et al, [10], used the L27 orthogonal array experimental design to investigate the effect of cutting speed, feed rate and depth of cut on surface roughness under different cutting fluid in turning AISI 1330 alloy steel. They employed the statistical methods of Signal-toNoise (S/N) ratio and the Analysis of Variance (ANOVA) to analyze their data. On the application of groundnut oil based cutting fluid to obtain a better surface roughness, the result obtained showed that feed rate was the most significant parameter in the turning operation. Salah et al, [11], applied the L27 fractional factorial array and described the outcome of the experimental results obtained in the turning of Ti-6Al-4V using watermiscible vegetable oil (VOs)-based cutting fluid. Evaluation of the effects of cutting fluid concentration and machining conditions on average surface roughness ( $R$ a) and microhardness showed that higher cutting speed produced slightly higher surface roughness with prolonging cutting distance. A combination of VOs-based fluid concentration (10\%), high cutting speed $(146 \mathrm{~m} / \mathrm{min})$ and feed rate $(0.1 \mathrm{~mm} / \mathrm{rev})$ produced the lowest average surface roughness $(\mathrm{Ra})$. It was concluded that $10 \%$ concentration showed a marginal improvement in Ra compared to $5 \%$. However, $5 \%$ concentration is preferred for cost effective concentration ratio with less base oil consumption, which is more environmentally friendly. Thus, cutting fluid concentration is a significant factor for reducing surface roughness Ra-value. These studies showed the effectiveness of the and factorial design for application in the analysis of cutting tool parameters and hence, the present study applies these experimental design tools to investigate on the effect of Apricot kernel oil on the surface temperature, roughness and chip thickness during turning of $\phi$ 25 mm AISI 1020 Steel with high speed steel (HSS) cutting tool.

\section{EXPERIMENTAL}




\subsection{Materials / Equipment}

Materials and equipment details used for this study are the same as described in Eziwhuo et al [1]. Apricot kernel oil (AKO) vegetable-based cutting fluid with $40 \%$ (volume) additives blend was found to give the best performance and was used to study the effect of cutting parameters for turning of AISI 1020 stainless steel. The apricot base oil in Fig. 1(c) was extracted by cold pressing of the crushed and grinded apricot kernels (Fig. 1(b)) which were obtained after consuming the apricot fruit in Fig. 1(a).

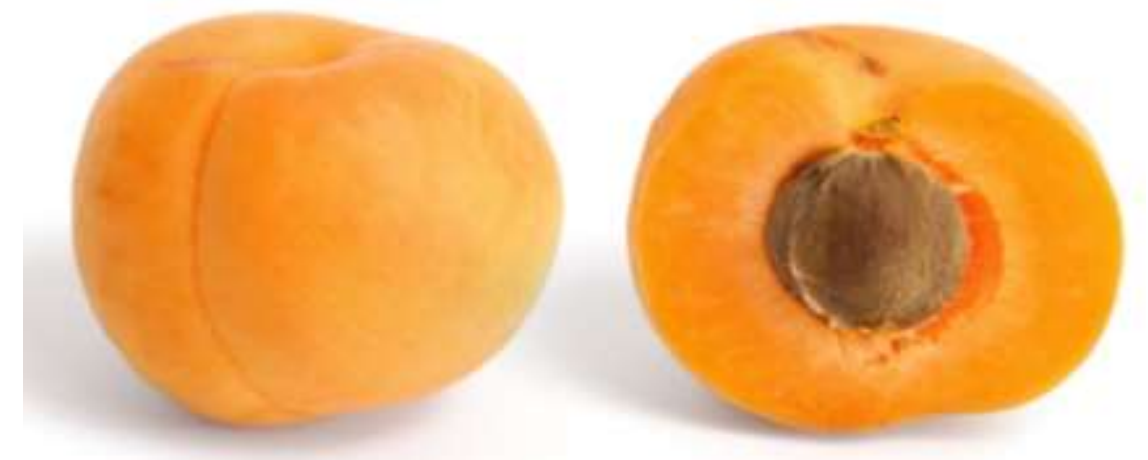

(a)

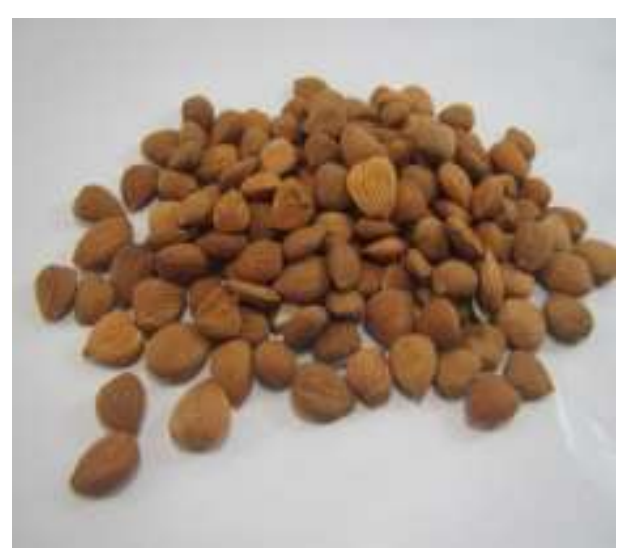

(b)

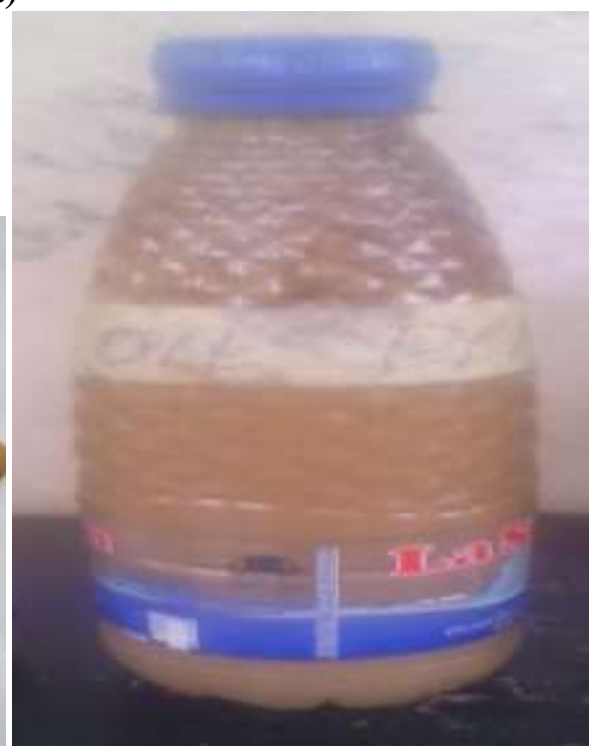

(c)

Fig. 1: (a) Apricot fruit with seed / kernel, (b) Apricot kernel / seed, and (c) raw extracted base oil.

This base oil extracted was used to formulate the green / organic cutting fluids by mixing with relevant additives. The formulated cutting fluids were comprised of $40 \%$ additives (10 \% washing soap, $20 \%$ tri-ethanol amine and $10 \%$ water) and $60 \%$ base-oil (raw AKO for the VBCF and non-additive base oil for the hydrocarbon-based cutting fluid HBCF). The HBCF was used as the control fluid and it was purchased from the local market. The formulated cutting fluids were applied by gravity feeding in the turning of AISI 1020 mild steel on a conventional lathe (Lagun, UK) with high speed steel cutting tool. The evaluation criteria included: interface surface temperature measured by infrared non-contact thermometer (Rycon JXB-181, China), surface roughness by surface finish tester (ISR-16, UK) with diamond stylus tip, and chip thickness by stainless steel Vernier caliper (More \& Wright, $U K$ ). All samples were $\phi 25 \mathrm{~mm}$ smooth AISI 1020 mild steel rods that were turned on conventional centre lathe machine following the L27 orthogonal array design of experiment runs as shown in Table 1 and Table 2. 


\subsection{Methods}

\subsubsection{Independent Variables Coding}

The parameters of interest in this study were sliding speed, cutting time and cutting depth. These were considered as actual control variables $X_{\text {aj }}$ as shown in equation (1), where $X_{\mathrm{sj}}$, $X_{t j}$ and $X_{d j}$ represent the speed, time and cutting depth respectively; each with 3-levels and numerical values: 90, 125, and 160rpm for sliding speed $X_{\mathrm{sj}}, 2,4$ and 6minutes for cutting time $X_{\mathrm{tj}}$, and 1,2 and $3 \mathrm{~mm}$ for cutting depth $X_{\mathrm{dj}}$.

$X_{a j}=\left[\begin{array}{l}X_{s j} \\ X_{t j} \\ X_{d j}\end{array}\right]=\left[\begin{array}{ccc}90 & 125 & 160 \\ 2 & 4 & 6 \\ 1 & 2 & 3\end{array}\right]$

To reduce the influence of weight in the model, the actual independent control variables used were coded and normalized. Transformation equation for the coding are shown in equations (2) - (4) with speed control variable $X_{1}$, cutting time control variable $X_{2}$, and cutting depth control variable $X_{3}$.

$X_{1}=\frac{X_{s}-125}{35}$

$X_{2}=\frac{X_{t}-4}{2}$

$X_{3}=X_{d}-2$

Where,

$X_{s}, X_{t}$ and $X_{d}$ are the sliding speed, cutting time, and cutting depth, respectively. Hence, substituting the values of equation (1) into equations (2-4) yields the coded independent control variables in equation (5)

$X_{c j}=\left[\begin{array}{l}X_{1 j} \\ X_{2 j} \\ X_{3 j}\end{array}\right]=\left[\begin{array}{lll}-1 & 0 & 1 \\ -1 & 0 & 1 \\ -1 & 0 & 1\end{array}\right]$

The general model for the following responses: surface temperature Xst, surface roughness $X_{S R}$, and chip thickness $X_{C T}$, based on the cutting process parameters is as shown in equation (6), with 3 as the highest level of interactions for the turning parameters.

$y=b_{o}+\sum_{i=1}^{3} b_{i} X_{i}+\sum_{i \neq} \sum_{j=1}^{3} b_{i j} X_{i} X_{j}+\sum_{j=1}^{3} b_{j j} X_{j}^{2}$

Where $b_{o}, b_{i}, b_{i j}$, and $b_{j j}$ are the intercept, main effect, interaction effect, and quadratic effects of the model, respectively. Expanding equation (6) gives equation (7),

$$
\begin{gathered}
y=b_{o}+b_{1} X_{1}+b_{2} X_{2}+b_{3} X_{3}+b_{12} X_{1} X_{2}+b_{23} X_{2} X_{3}+b_{13} X_{1} X_{3}+b_{11} X_{1}{ }^{2}+b_{22} X_{2}{ }^{2} \\
+b_{33} X_{3}{ }^{2}
\end{gathered}
$$

\subsubsection{Design of Experiment and Test Procedures}

The L27 orthogonal array was used for the design of the experiment (DOE) based on the control (process) variables used as input and the evaluation criteria of surface temperature $X_{S T}$, surface roughness $X_{S R}$ and chip thickness $X_{C T}$ used as the response outcomes. The input (independent) variables are set on the machine following the L27 orthogonal array design of experiment (DOE) where columns 2, 3 and 4 are for each experimental run of Table 1 and Table 2.

\section{RESULTS AND DISCUSSIONS \\ 3.1 Response Output (Outcomes)}


At the end of each experiment, the outputs, surface temperature $X_{S T}$, roughness $X_{S R}$ and chip thickness $X_{C T}$ measured and recorded are presented in columns 5, 6 and 7 of Table 1 (for AKO VBCF) and Table 2 (for HBCF).

\subsubsection{Surface Temperature}

Surface temperature $\left({ }^{\circ} \mathrm{C}\right)$ contours from the actual experimental runs are shown in Fig. 2a for the lower sliding speed range (90rpm) and Fig. $2 \mathrm{~b}$ for the higher sliding speed range (160rpm) with respect to cutting time and cutting depth.

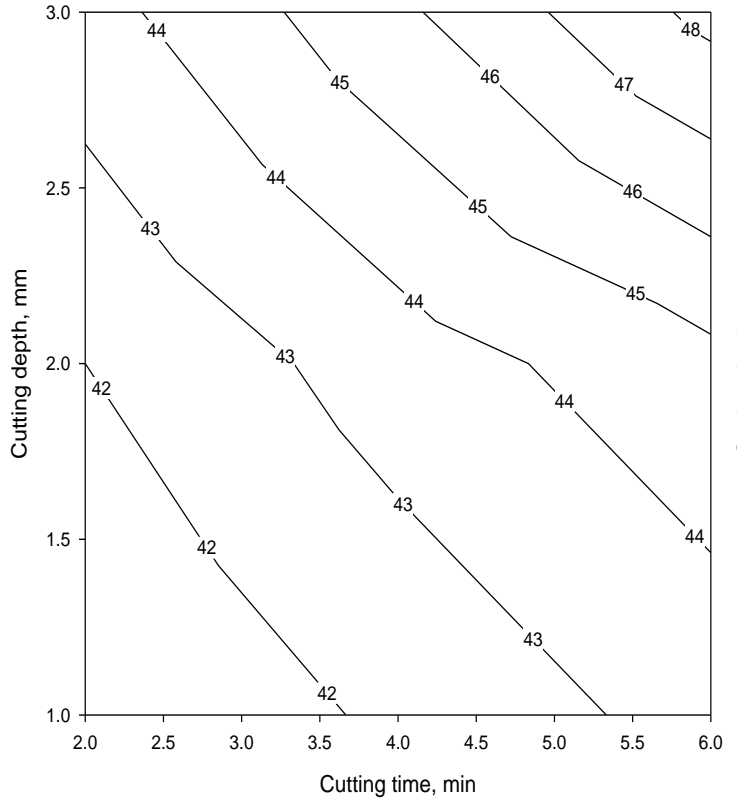

(a)

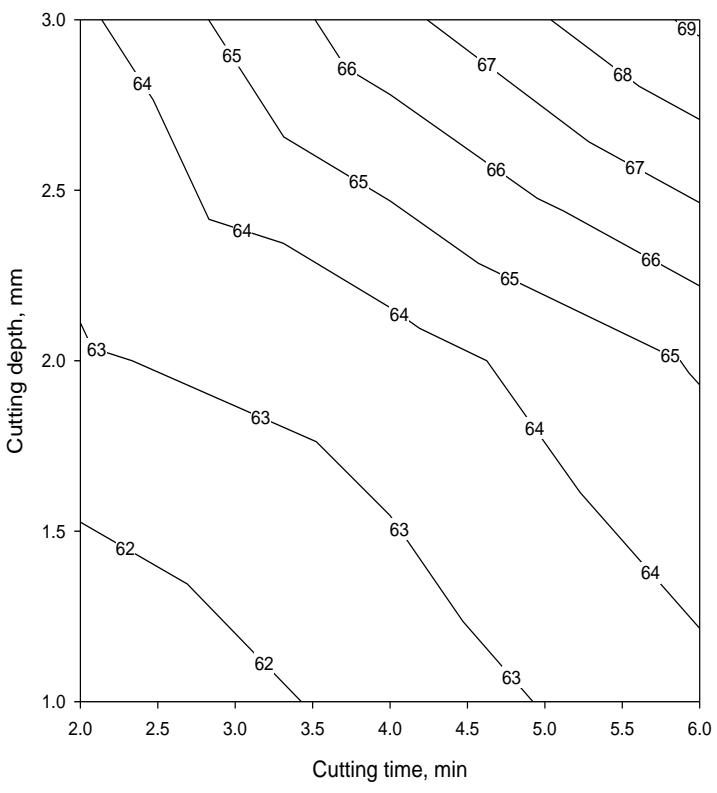

(b)

Fig. 2 AKO VBCF Surface temperature contour.

A heat plateau within the region $2.0<X_{d} \leq 3.0$, and $4.0<X_{t} \leq 6.0$, was observed in Fig. 2a and a heat steep occurred as temperature contour ascent against the gradual slopes (almost a saddle) outside these regions. Relatively speaking, the heat ascent region observed within the 160rpm sliding speed in Fig. $2 \mathrm{~b}$ is much larger than the heat ascent observed in the 90rpm speed of Fig. 2a. As observed in Eziwhuo et al, [1], the high heat ascent associated with the $160 \mathrm{rpm}$ in Fig. $2 \mathrm{~b}$ was attributed to reduced cooling (quenching) with time as the cutting fluid was carried away too quickly from the cutting interface before appreciable cooling was observed on the work piece. A clearer view of these phenomena is shown on a temperature response surfaces (Fig. 3). The $90 \mathrm{rpm}$ speed response is within the temperature range of $45-50^{\circ} \mathrm{C}$ below the $160 \mathrm{rpm}$ response surface at a temperature range of between 60 and $65^{\circ} \mathrm{C}$. 


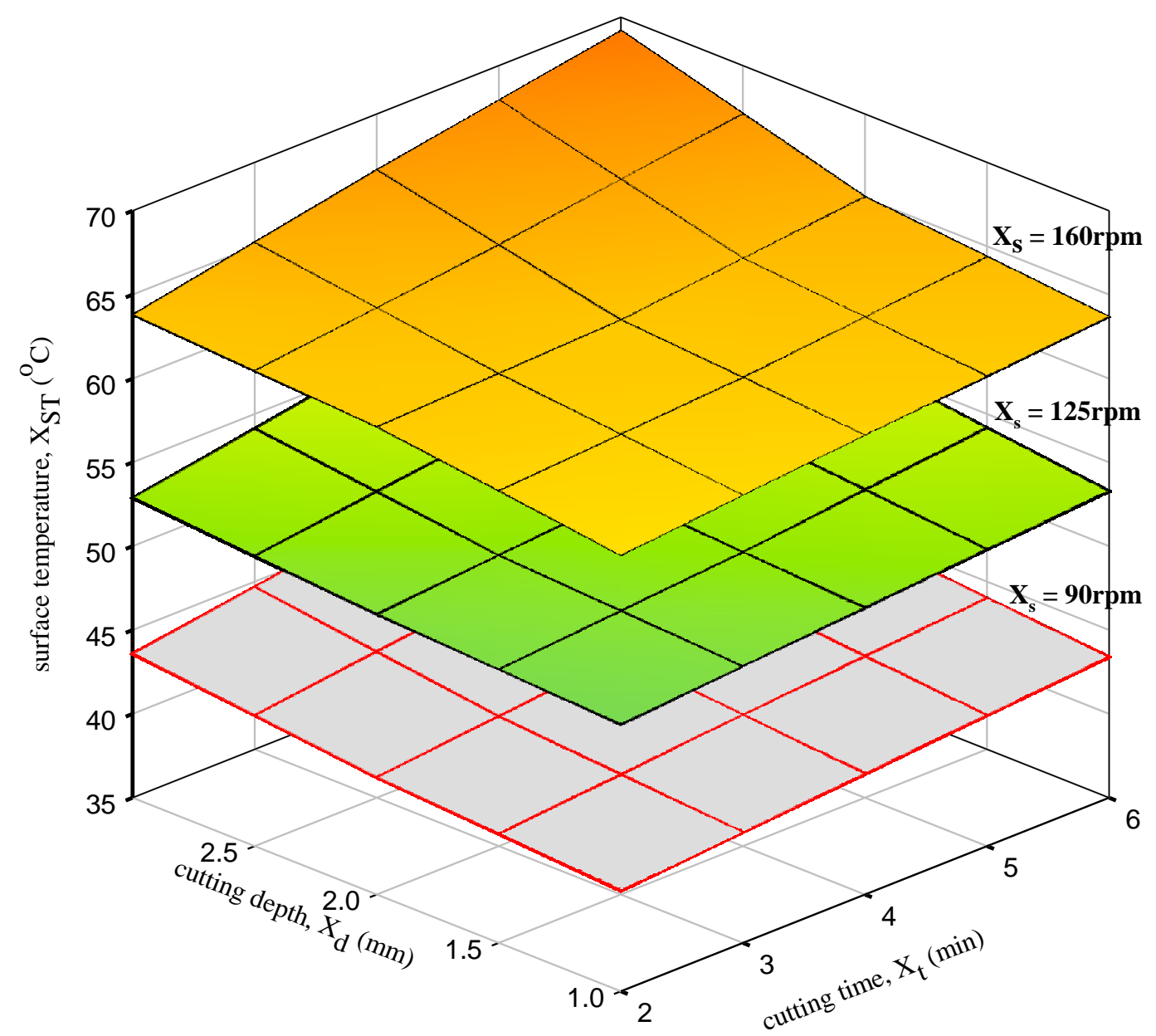

Fig. 3 AKO VBCF temperature response surfaces variation with cutting depth, time and sliding speed.

\subsubsection{Surface Roughness}

The surface roughness variation with respect to cutting depth and cutting time measured and recorded for 90rpm and $160 \mathrm{rpm}$ speed are shown in Fig. $4 \mathrm{a}$ and Fig. $4 \mathrm{~b}$. The $90 \mathrm{rpm}$ speed showed that a direct proportionality exists between the cutting depth and time within the surface roughness values measured and the contour lines are uniformly space. This shows that at low speed, there is high waviness with crest or trough on the work piece surface compared to high speed. Thus, Fig. 4a has the highest surface roughness and positive sloping compared to the 160rpm where the surface roughness variation with cutting depth and cutting time below cutting depth of $2.0 \mathrm{~mm}$ was irregular. This is an indication that surface roughness at 160rpm has a region of high and low waviness, which made the surface better than the wide and continuous wavy surface of the $90 \mathrm{rpm}$ speed. The effect of the cutting depth (Fig. 4b), the contour line at a cutting depth of $2 \mathrm{~mm}$ and time 4min, exhibited a zero slope. Before this contour slope rose with time (positive slope) but beyond which contour slope falls with time (negative slope) at this $160 \mathrm{rpm}$ speed. 


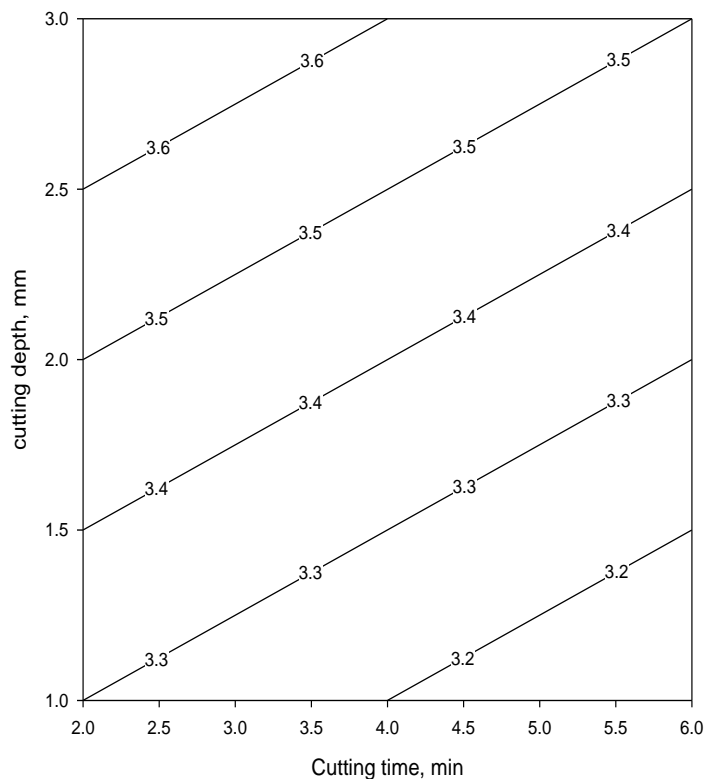

(a)

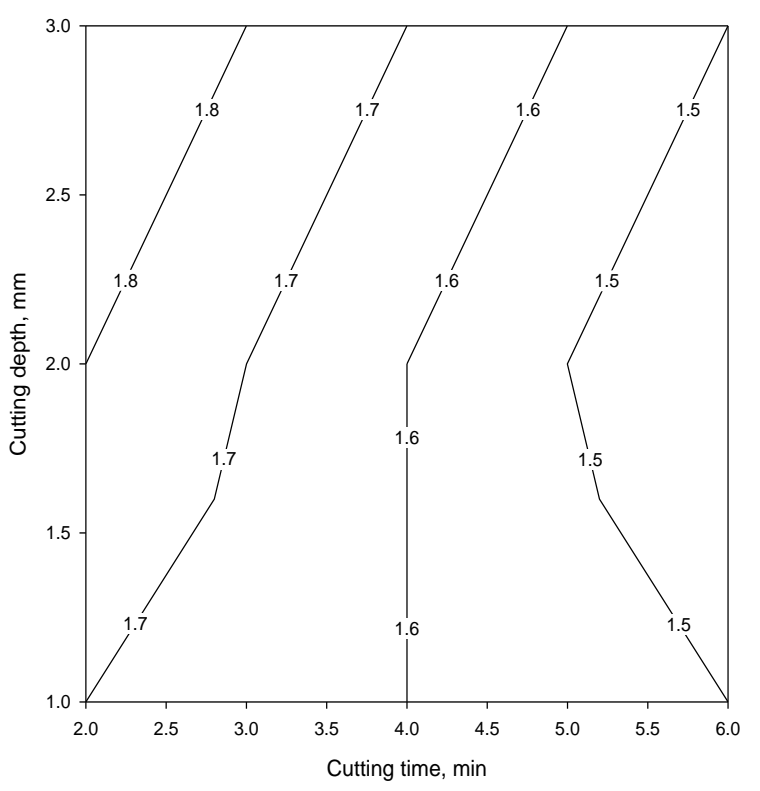

(b)

Fig. 4 AKO VBCF surface roughness contours for (a) 90rpm and (b) 160rpm.

The non-linearity in the surface roughness contour lines of Fig. $4 \mathrm{~b}$ in the region $X_{t}>4 \mathrm{~min}$ is due to insufficient quenching of the frictionally heated interface, which would have led to change in the microstructure of the interface. However, this was not investigated further by surface characterization of the machined surfaces by imaging. From Fig. 5 the roughness response surface for $90 \mathrm{rpm}$ is above that $125 \mathrm{rpm}$ and $160 \mathrm{rpm}$. This indicated that the surface finish was reduced as the speed increased. In other words, the effect of sliding speed on the surface roughness is such that a higher speed causes lower roughness (higher interface lubricity) and a lower speed causes higher roughness (lower interface lubricity).

Though friction phenomenon does not strictly follow the surface roughness theory (jigsaw puzzle), it has been known that interacting rougher surfaces are associated with higher friction, though not exactly by the mechanism postulated by the theory. Figure 5 showed that higher cutting speeds generated smoother surface finish. With higher turning speed there is less quenching time of the workpiece interface by the application of the cutting fluids. The interfacial shear strength of the softer workpiece material is therefore reduced and the friction is increased following the simple adhesion friction theory. The converse is true for lower cutting speed, higher quenching time, higher interfacial shear strength and lower friction (lower surface roughness - smoother surface finish). Bowden and Tabor [12] and Czichos, [13], reported that friction reduces with sliding speed though not proportionately but following an exponential decay from the static friction value. 


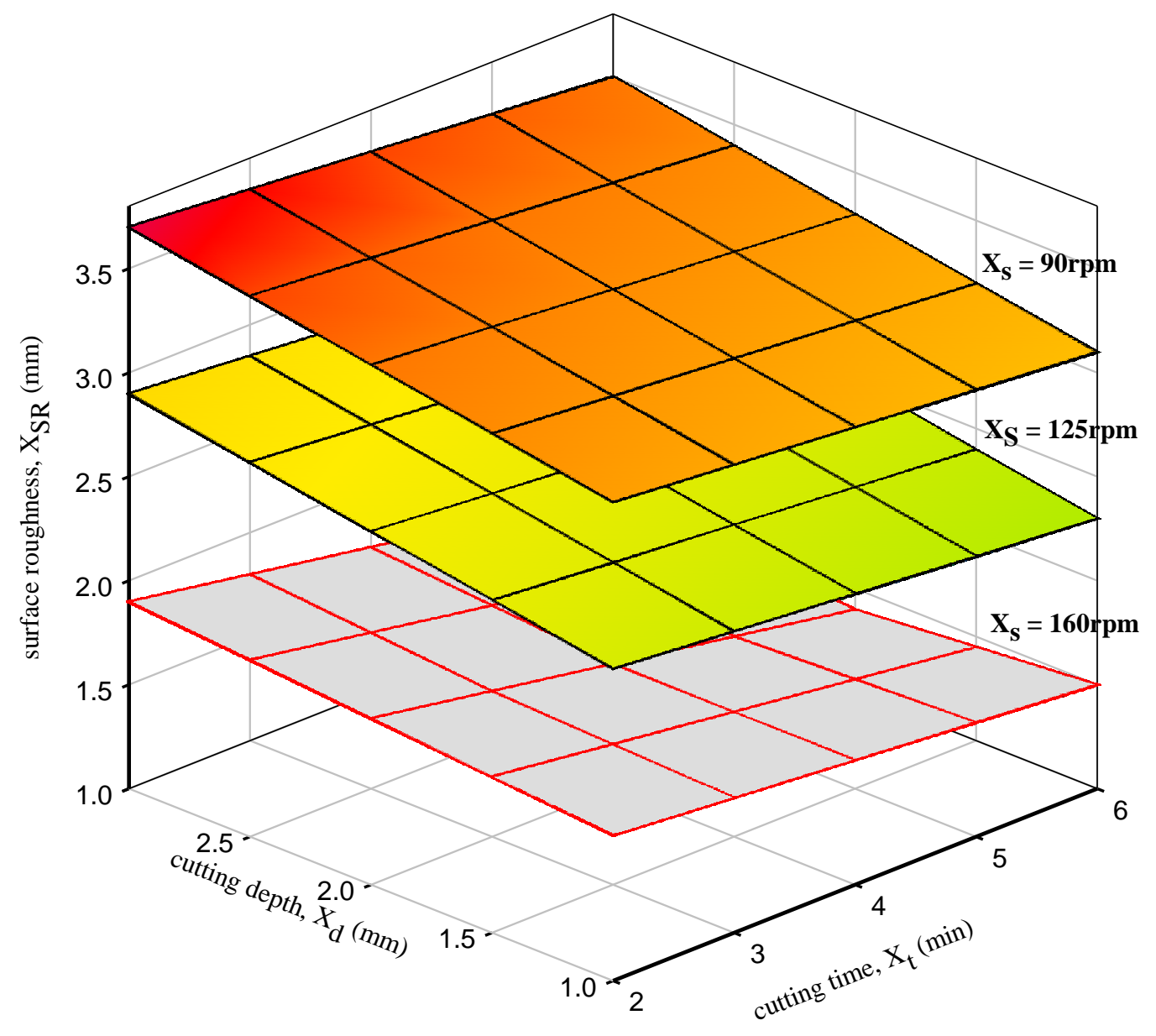

Fig. 5 Surface roughness variation with sliding speed, cutting depth and time for AKO VBCF.

\subsubsection{Chip thickness}

From Fig. 6 and Fig. 7 the chip thickness produced by machining of AISI 1020 steel using HSS cutting tool increased with the turning speed. In the same vein, the chip thickness also increases with cutting time and cutting depth. The order of increase of chip thickness with respect to cutting depth is almost 10-times more than that of cutting time. Expectedly, as the interfacial frictional heating continues, less heat is carried away from the interface by conduction and convection leading to increase in localized melting of the workpiece and oxidation of the transferred material can lead to this increased chip thickness compared to prevalent thickness at the beginning of the cutting process.

\subsection{Response Surface models}

The different response outcomes, surface temperature, surface roughness (finish) and chip thickness obtained using the VBCF and HBCF were modelled as functions of the coded independent (process) variables $\left(X_{1}, X_{2}\right.$ and $\left.X_{3}\right)$, and hence functions of the actual control variables of cutting speed $X_{s}$, cutting time $X_{t}$ and cutting depth $X_{d}$ as shown in Table 3. 


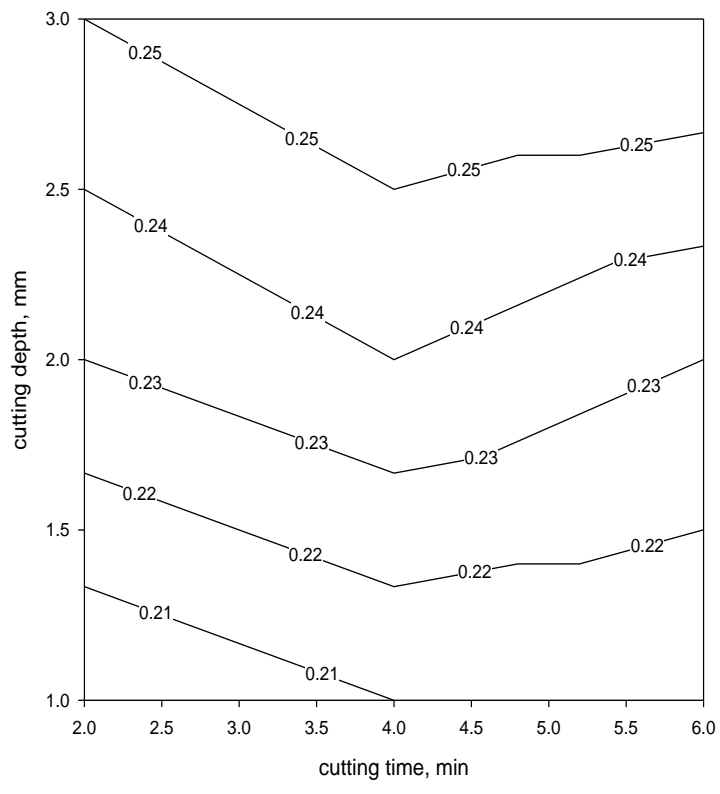

(a)

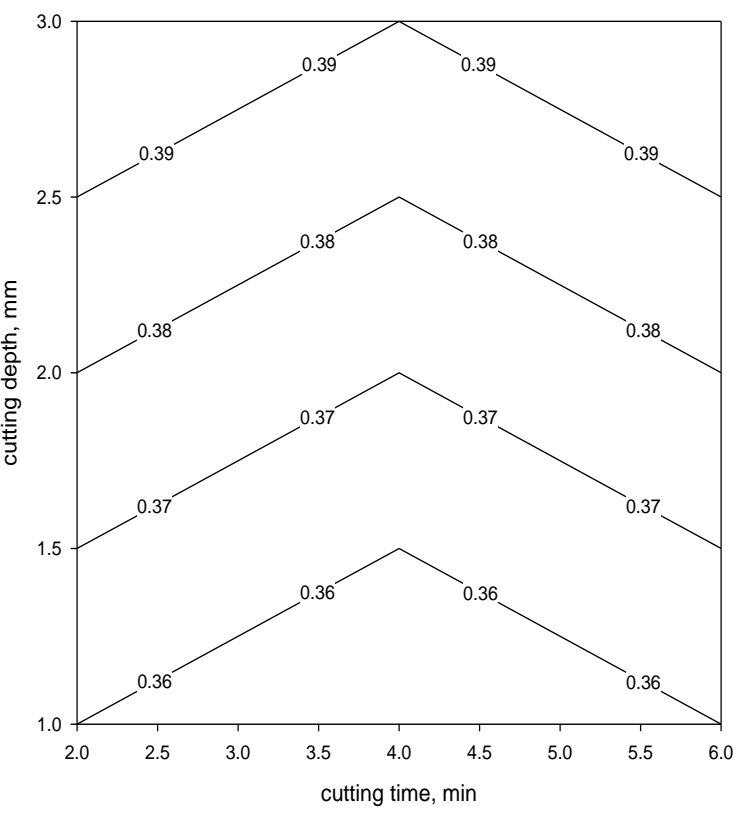

(b)

Fig. 6 chip thickness contours at (a) $90 \mathrm{rpm}$ and (b) $160 \mathrm{rpm}$ for AKO VBCF.

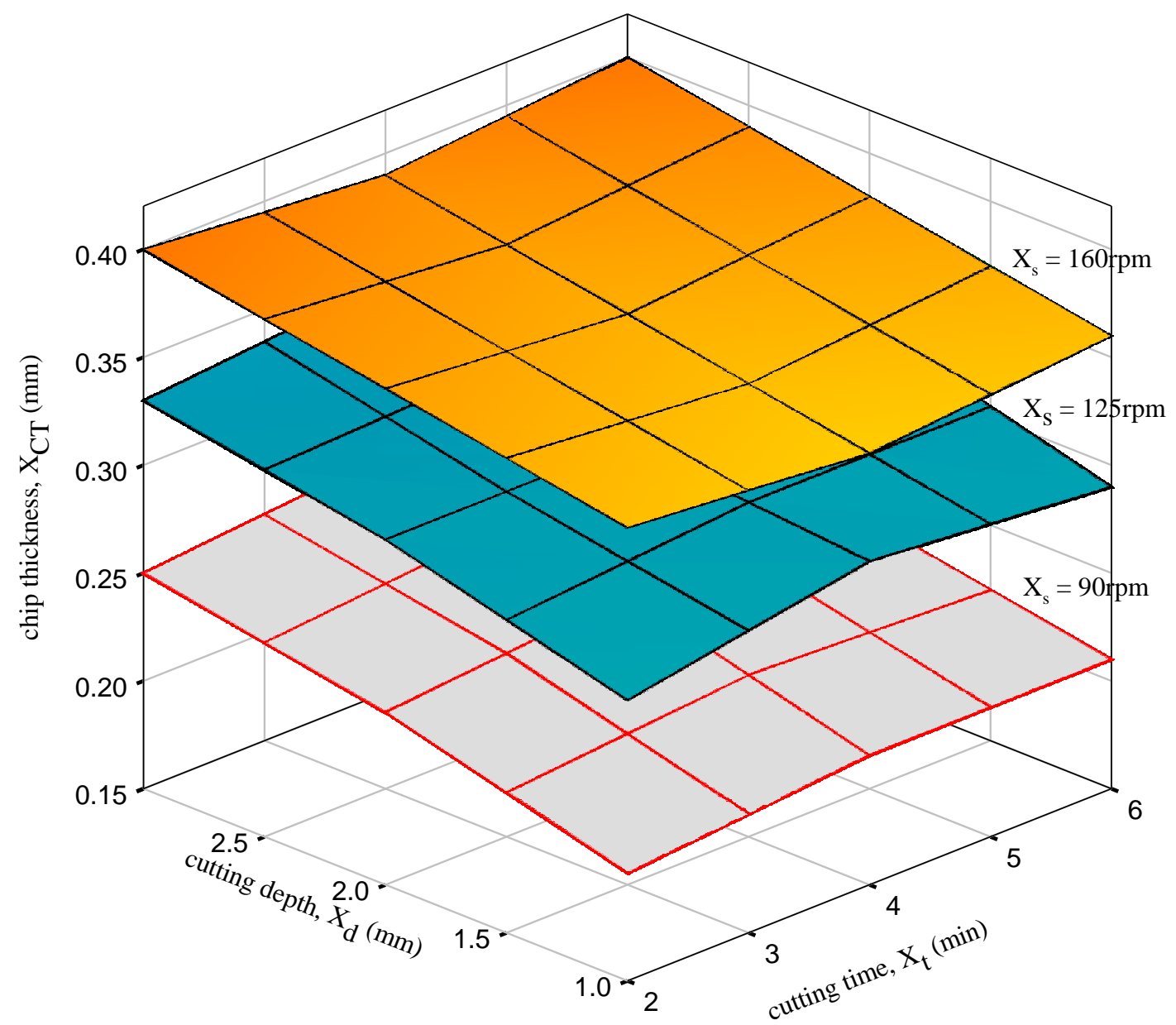

Fig. 7 chip thickness variation with sliding speed, cutting depth and time for AKO VBCF. 
Table 3 Response models of the cutting fluid performance parameters for AKO VBCF and HBCF.

\begin{tabular}{|c|c|c|c|c|}
\hline $\begin{array}{c}\text { Cutting } \\
\text { fluid }\end{array}$ & Parameter / Model & $\begin{array}{c}\mathbf{R}^{2}- \\
\text { value }\end{array}$ & $\begin{array}{c}\text { Standard } \\
\text { Error \& }\end{array}$ & $\begin{array}{c}\text { Signif. } \\
\text { F }\end{array}$ \\
\hline \multicolumn{5}{|c|}{ Surface Temperature } \\
\hline $\begin{array}{l}\text { AKO } \\
\text { VBCF }\end{array}$ & $\begin{array}{c}53.1926+10.2056 X_{1}+1.7722 X_{2} \\
+1.9278 X_{3}+0.725 X_{2} X_{3} \\
+0.6389 X_{3}^{2}\end{array}$ & 0.9986 & 0.4084 & $\begin{array}{l}2.02 E- \\
22\end{array}$ \\
\hline HBCF & $\begin{aligned} 52.7111+6.6556 X_{1}+1.15 X_{2} \\
+1.1056 X_{3}+0.4583 X_{1} X_{2} \\
+0.4333 X_{2} X_{3}+0.35 X_{1} X_{3}\end{aligned}$ & 0.9943 & 0.5364 & $\begin{array}{l}2.93 E- \\
17\end{array}$ \\
\hline \multicolumn{5}{|c|}{$\begin{array}{l}\text { Surface roughness } \\
\end{array}$} \\
\hline $\begin{array}{l}\text { AKO } \\
\text { VBCF }\end{array}$ & $\begin{aligned} 2.5889-0.8833 X_{1}-0.1222 X_{2} \\
+0.15 X_{3}-0.0333 X_{1} X_{2} \\
-0.075 X_{1} X_{3}-0.0833 X_{1}^{2}\end{aligned}$ & 0.9973 & 0.0487 & $\begin{array}{l}5.11 E- \\
20\end{array}$ \\
\hline HBCF & $\begin{array}{r}1.6889-0.5667 X_{1}-0.1222 X_{2} \\
+0.1278 X_{3}+0.1333 X_{1}{ }^{2}\end{array}$ & 0.9867 & 0.0716 & $\begin{array}{l}3.7 \mathrm{E}- \\
14\end{array}$ \\
\hline \multicolumn{5}{|c|}{$\begin{array}{ll}\text { Chip thickness } \\
\end{array}$} \\
\hline $\begin{array}{l}\text { AKO } \\
\text { VBCF }\end{array}$ & $\begin{array}{c}0.3137+0.0722 X_{1}+0.0222 X_{3} \\
-0.0078 X_{1}^{2} \\
\end{array}$ & 0.9942 & 0.0060 & $\begin{array}{l}3.25 \mathrm{E}- \\
17\end{array}$ \\
\hline HBCF & $\begin{array}{r}0.2778+0.065 X_{1}+0.0222 X_{3} \\
-0.005 X_{1} X_{3}-0.0083 X_{1}{ }^{2}\end{array}$ & 0.9910 & 0.0068 & $\begin{array}{l}1.41 E- \\
15\end{array}$ \\
\hline
\end{tabular}

Typically, using multivariate regression analysis tool for the surface temperatures recorded in the use of $\mathrm{AKO} \mathrm{VBCF}$ in column 5 of Table 1, we obtained the surface temperature regression summary for $\mathrm{AKO} \mathrm{VBCF}$ as in Table 4. The regression showed very high significance with signif. $F=2.02 E-22$, coefficient determination $R^{2}=0.9986$, and standard error $\varepsilon=0.4084$.

Table 4: Surface Temperature Regression Summary for AKO VBCF ANOVA

\begin{tabular}{|c|c|c|c|c|c|}
\hline & $d f$ & $S S$ & $M S$ & $F$ & Signif. $F$ \\
\hline Regression & 9 & 2007.967 & 223.1075 & 1337.508 & 2.02E-22 \\
\hline Residual & 17 & 2.835741 & 0.166808 & & \\
\hline Total & 26 & 2010.803 & & & \\
\hline Variables & Coefficients & Std Error & $t$ Stat & P-value & \\
\hline $\mathbf{b}_{\mathrm{o}}$ & 53.19259 & 0.207958 & 255.7851 & 6.37E-32 & \\
\hline $\mathbf{X}_{1}$ & 10.20556 & 0.096266 & 106.0142 & 2.01E-25 & \\
\hline $\mathbf{X}_{2}$ & 1.772222 & 0.096266 & 18.40965 & 1.15E-12 & \\
\hline $\mathbf{X}_{3}$ & 1.927778 & 0.096266 & 20.02555 & 2.93E-13 & \\
\hline$X_{1} X_{2}$ & 0.05 & 0.117901 & 0.424084 & 0.676822 & \\
\hline $\mathbf{X}_{2} \mathbf{X}_{3}$ & 0.725 & 0.117901 & 6.149217 & 1.07E-05 & \\
\hline$X_{1} X_{3}$ & 0.125 & 0.117901 & 1.06021 & 0.303881 & \\
\hline$X_{1}^{2}$ & 0.338889 & 0.166737 & 2.03247 & 0.058031 & \\
\hline$X_{2}^{2}$ & 0.138889 & 0.166737 & 0.83298 & 0.416406 & \\
\hline $\mathbf{X}_{3^{2}}$ & 0.638889 & 0.166737 & 3.831706 & 0.001336 & \\
\hline
\end{tabular}

From Table 4, since the $p$-value $>0.0500$ for variables $X_{1} X_{2}, X_{1} X_{3}, X_{1}{ }^{2}$, and $X_{2}{ }^{2}$ (italicized) were insignificant $p$-values based on $95 \%$ confidence interval, their coefficients were 
neglected to model the cooling response for AKO VBCF shown in row-3, column 2 of Table 3 and as equation (8).

$$
\begin{gathered}
X_{S T}=53.1926+10.2056 X_{1}+1.7722 X_{2}+1.9278 X_{3}+0.725 X_{2} X_{3} \\
+0.6389 X_{3}^{2}
\end{gathered}
$$

Where, $X_{1}, X_{2}, X_{3}$ are the independent coded variables corresponding to control variables $X_{s}, X_{t}$, and $X_{d}$ given by equations (2), (3) and (4), respectively. The same procedure was applied to the response outcomes of surface roughness $X_{S R}$, and chip thickness $X_{C T}$ using both AKO VBCF and HBCF to obtain all the other models, $R^{2}$, standard error $\varepsilon$ and significance F-values shown in Table 3.

\subsection{Main, interaction and quadratic effects of models}

From the models in Table 3, it can be observed that all the main effects of each process variable $\left(X_{s}, X_{t}, X_{d}\right)$ on the output variables $\left(X_{S T}, X_{S R}, X_{C T}\right)$ were the same (positive or negative) for both $\mathrm{AKO} \mathrm{VBCF}$ and $\mathrm{HBCF}$ in all the models, indicating that the mechanism of functionality were similar. AKO VBCF showed higher main effects and intercepts for all output surface temperature, roughness and chip thickness compared to HBCF. This implies that VBCF possessed superior cooling characteristics but inferior lubricity (rougher surface interface) at the tribological interface. The transportation properties of both cutting fluids (AKO VBCF and HBCF) are of similar order, based on the order of the coefficients of the chip thickness models.

\subsubsection{Surface Temperature}

From the coefficients values of the AKO VBCF temperature model, rotating speed $X_{s}$ showed the greatest main effect on cooling response of the tribo-pairs, followed by cutting depth $X_{d}$ and then cutting time $X_{t}$. From this AKO VBCF model (equation (8)), there was positive interaction between the cutting depth and time, with an interaction effect of 0.725 and a positive quadratic effect of cutting depth value of 0.6389 . The coefficients values of the HBCF temperature model, rotating speed $X_{s}$ showed the greatest main positive effect on surface temperature of the tribo-pairs, followed by cutting time $X_{t}$ and cutting depth $X_{d}$. Also, there was positive interaction effect between the cutting speed $X_{s}$ and time $X_{t}$ $(0.4583)$, cutting time $X_{t}$ and depth $X_{d}(0.4333)$ and; cutting speed $X_{s}$ and depth $X_{d}(0.350)$.

\subsubsection{Surface roughness}

The AKO VBCF roughness model, rotating speed $X_{s}$ showed the greatest negative main effect (-0.8833), followed by a positive main effect ( 0.1500$)$ of cutting depth, and negative main effect (-0.1222) of cutting time $X_{t}$ on surface roughness. The negative effect implied that an increase in speed (for example) will give a decrease in surface roughness and viceversa. From this model, there was negative interaction between cutting speed - cutting depth $X_{s} X_{d}(-0.075)$ and a lesser negative interaction $(-0.0333)$ between cutting speed cutting time $X_{s} X_{t}$, and a negative quadratic interaction effect of cutting speed (-0.0833).

Based coefficients values of the $\mathrm{HBCF}$ model, rotating speed $X_{\mathrm{s}}$ showed the greatest negative effect (-0.5667), followed by cutting time $X_{t}$ negative effect (-0.1222) and a positive main effect $(0.1278)$ of cutting depth on surface roughness but a positive quadratic effect of cutting speed ( 0.1333$)$.

\subsubsection{Chip thickness}


From the coefficients values of the AKO VBCF chip thickness model, rotating speed $X_{s}$ showed the greatest positive effect $(0.0722)$ on chip thickness of the tribo-pairs, followed by cutting depth $X_{d}(0.0222)$. From this model, there was no interaction effect between the process variables but a subtractive quadratic effect $(\mathbf{- 0 . 0 0 7 8 )}$ of cutting speed. The coefficients values of $\mathrm{HBCF}$ model showed that rotating speed $\mathrm{X}_{\mathrm{s}}$ indicated the greatest positive effect $(0.065)$ on chip thickness of the tribo-pairs, followed by cutting depth $X_{d}$ $(0.0222)$. There was a negative interaction effect $(-0.005)$ between cutting speed $X_{s}$ and cutting depth $X_{d}$, but a subtractive quadratic effect (-0.0083) of cutting speed. Both AKO VBCF and HBCF chip thickness models showed that the chip thickness $X_{C T}$ was independent of the cutting time $X_{t}$.

\subsection{Measured and predicted performance response surfaces}

It is obvious from Fig. 8 that Apricot kernel oil-based cutting fluid showed superior cooling characteristics compared to the hydrocarbon-based cutting fluid (control). This trend was observed to change at higher cutting speed range $125<X_{\mathrm{s}} \leq 160 \mathrm{rpm}$.

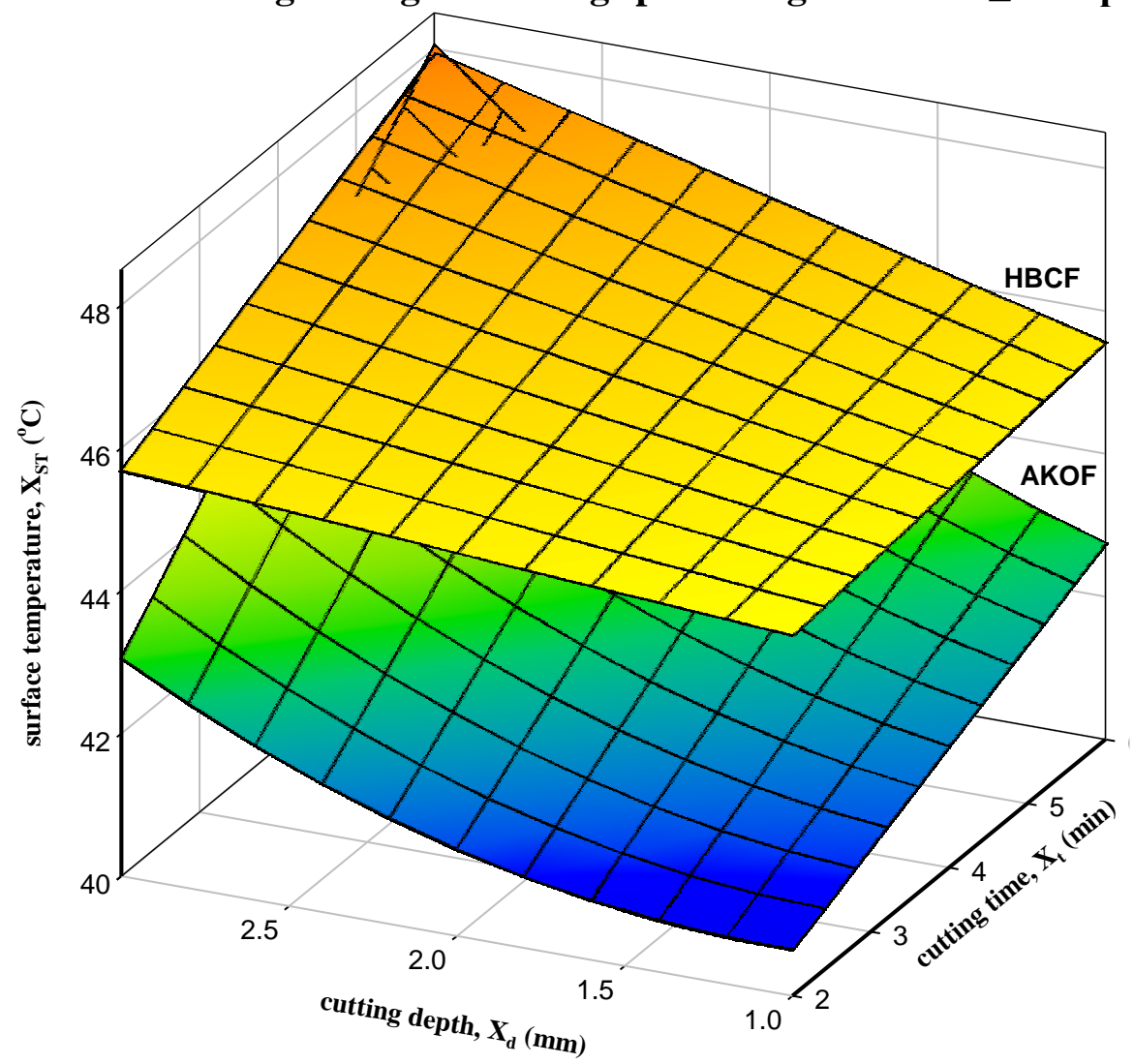

Fig. 8 Cooling response of $\mathrm{AKO} \mathrm{VBCF}$ and control $\mathrm{HBCF}$ at $90 \mathrm{rpm}$.

To evaluate the performance of the $\mathrm{AKO} \mathrm{VBCF}$ relative to a control cutting fluid, we define a criterion known as cutting fluid performance index $(\beta)$, which is the ratio of the performance parameter of a VBCF to the performance of an equivalent HBCF. For instance, the surface temperature performance index ( $\left.\beta_{S T}\right)$ for Apricot based cutting fluid is the ratio of surface temperatures obtained using AKO VBCF divided by the surface temperature obtained using hydrocarbon-based cutting fluid. This implies that a VBCF with better performance than HBCF should have a performance index that is less than unity and vice versa. Therefore, comparing AKO VBCF and HBCF based on the surface temperature response in Fig. 8, performance index $\beta_{S T}$ range obtained was $0.90 \leq \beta_{S T} \leq 1$. 


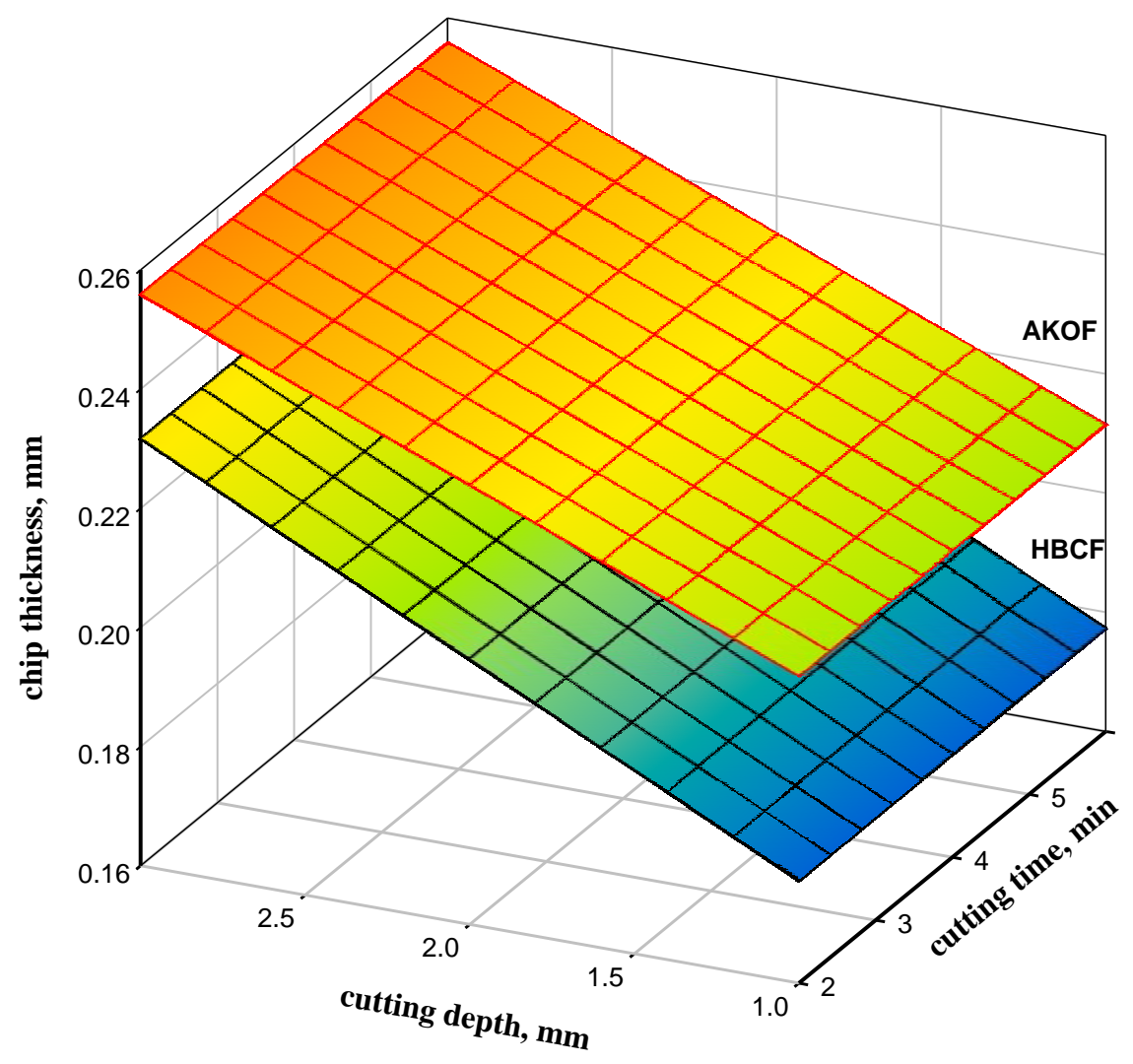

Fig. 9 Chip thickness response of AKO VBCF and control HBCF at $90 \mathrm{rpm}$.

However, based on the chip thickness response criterion in Fig. 9, the performance index $\beta_{\mathrm{CT}}$ range was $1.104 \leq \beta_{\mathrm{CT}} \leq 1.193$ but for the surface roughness criterion the performance index $\beta_{\mathrm{SR}}$ range was $1.365 \leq \beta_{\mathrm{SR}} \leq 1.472$. These shows that the vegetable-based cutting fluid exhibited a superior performance index, less than unity, in cooling (surface temperature) response but inferior index in surface finish (roughness) and chip thickness transportation at 90rpm sliding speed.

All predicted RSMs showed close fitness relationship with the actual RSMs following the pattern in Fig. 10 where a coefficient of determination of $R^{2}=0.9986$ was obtained with a sliding speed of 90rpm for AKO VBCF. Recall from section 3.2.3 that the $R^{2}$-values of all the response models were in the range $0.9867 \leq R^{2} \leq 0.9986$ while the standard error $\varepsilon$ of regression was in the range $0.0060 \leq \varepsilon \leq 0.5364$ which were quite acceptable regression values.

Similar trends of close fitness between predicted RSMs and actual experimental RSMs were observed for the outcome parameters irrespective of the cutting fluids applied as indicated by the coefficient of determination of $R^{2} \geq 0.9867$ for surface roughness $X_{S R}$ and $R^{2} \geq 0.9910$ for chip thickness $X_{C T}$. 


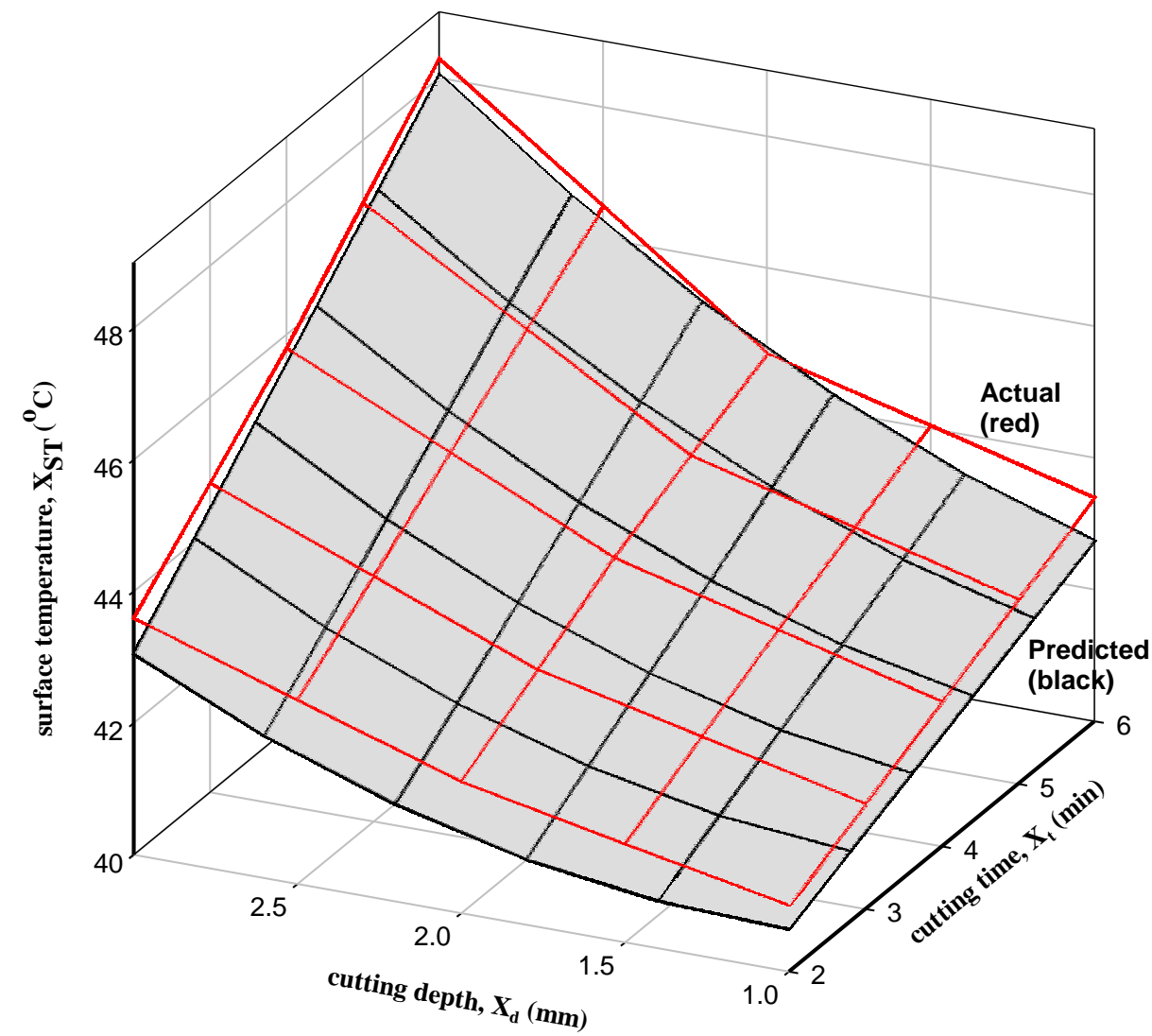

Fig. 10 Predicted and actual temperature RSM at 90rpm for AKO VBCF for $R^{2}=$

4. CONCLUSIONS

0.9986.

The effect of sliding speed $X_{s}$, cutting time $X_{t}$ and cutting depth $X_{d}$ on the surface temperature $\left(X_{S T}\right)$, surface roughness $\left(X_{S R}\right)$, and chip thickness $\left(X_{C T}\right)$ in the turning of AISI 1020 steel have been investigated and it has been shown that the cutting process parameters have both negative and positive effects on the turning operation output. All the cutting process variables showed positive main effects on surface temperature, with rotating speed $\left(X_{s}\right)$ exhibiting the greatest effect. It was followed by cutting depth $\left(X_{d}\right)$, and cutting time $\left(\mathrm{X}_{\mathrm{t}}\right)$ for $\mathrm{AKO} \mathrm{VBCF}$, but the reverse was true for $\mathrm{HBCF}$.

The rotating speed $\left(X_{s}\right)$ showed higher negative main effect on surface roughness $X_{S R}$, followed by cutting time $\left(X_{t}\right)$. Only the cutting depth $\left(X_{d}\right)$ showed a positive main effect for both AKO VBCF and the control HBCF. The negative main effects of sliding speed and cutting time implied that an increase in speed and cutting time resulted in a decrease in surface roughness and vice-versa. However, for AKO VBCF there was negative quadratic effect of sliding speed unlike the control HBCF which showed a positive quadratic effect. There were no interaction effects between process variables in $\mathrm{HBCF}$ unlike AKO VBCF which showed negative interaction effects between sliding speed and cutting time, as well as, between sliding speed and cutting depth.

Both cutting fluids showed that chip thickness $X_{C T}$ was independent of cutting time $X$, being a function of sliding speed and cutting depth only. The main effect of sliding speed was greater than that of cutting depth $(\mathbf{0 . 0 2 2 2})$ in both hydrocarbon-based and Apricotbased machine cutting fluids, just as both exhibited negative quadratic effects for the sliding speed. AKO VBCF sliding speed main effect $(0.0722)$ was greater than that of the HBCF main effect $(0.065)$. 
Finally, it can be concluded from the developed mathematical models for surface roughness $\left(\mathrm{X}_{\mathrm{SR}}\right)$, surface temperature $\left(\mathrm{X}_{\mathrm{ST}}\right)$ and chip thickness $\left(\mathrm{X}_{\mathrm{CT}}\right)$ that a close agreement was observed between the predicted response and experimental results. Hence, the developed models can be used for the proper selection of cutting process conditions to assess product quality without the need to conduct trial experiments on difficult-to-cut or critical materials.

Funding

This research did not receive any specific grant from funding agencies in the public, commercial, or not-for-profit sectors.

\section{REFERENCES}

1. Eziwhuo S.J., Ossia C.V., Alibi S.I.; "Evaluation of Apricot kernel, Avocado and African pear seed oils as vegetable based cutting fluids in turning AISI 1020 steel", IOSR Journal of Engineering, 09(01) S1, 10-19, (2019).

2. Anshika, S., Devina, V., Anil, G., Manisha, K.; "Formulation and evaluation of wild apricot kernel oil based massage cream", Journal of Pharmacognosy and Phytochemistry 08(01), 1017-1021, (2019).

3. Gupta A, and Sharma, P.C.; "Standardization of methods for apricot kernel oil Extraction, packaging and storage", Journal Food Science Technology 46 (2):121-126, (2009).

4. Kaya C., Kola O., Ozer, M.S., Altan, A.; "Some Characteristics and Fatty Acids Composition of Wild Apricot (Prunus pseudoarmeniaca L.) Kernel Oil", Asian Journal of Chemistry, 20(4), 2597-2602, (2008).

5. Kate, A. E, Lohani, U. C, Pandey, J. P, Shahi, N. C, Sarkar, A.; "Traditional and mechanical method of the oil extraction from wild apricot kernel: A comparative study", Research Journal Chemical and Environmental Sciences. 2(2), 54-60, (2014).

6. Femenia A., Rosello C., Mulet A., Canellas J.; "Chemical composition of bitter and sweet apricot kernels", Journal of Agricultural Food Chemistry - American Chemical Society publication, 43(2), 356-361, (1995). https://doi.org/10.1021/jf00050a018

7. Ozkal, SG, Yener, M. E, Bayindirli, L.; "The solubility of apricot kernel oil in supercritical carbon dioxide". International Journal Food Science and Technology 41(4), 399-404, (2006). https://doi.org/10.1111/j.1365-2621.2005.01085.x.

8. Gupta A., Sharma P.C., Tilakratne B.M.K.S., Verma A.K.; "Studies on physicochemical characteristics and fatty acid composition of wild apricot (Prunus armeniaca Linn.) kernel oil", Indian Journal of Natural Products and Resources. 2012; 3(3), 366370, (2012). http://hdl.handle.net/123456789/14818

9. Kuram, E., Ozcelik, B., Demirbas, E., Sik, E., Tansel, I. N.; "Evaluation of New Vegetable-Based Cutting Fluids on Thrust Force and Surface Roughness in Drilling of AISI 304-Using Method", Materials \& manufacturing processes, 26(9), 1136-1146, (2015). http://dx.doi.org/10.1080/10426914.2010.536933 .

10. Onuoha, O.J., Abu, J.O., Lawal, S.A., Mudiare, E. and Adeyemi, M.B.; "Determining the Effect of Cutting Fluids on Surface Roughness in Turning AISI 1330 Alloy Steel Using Method", Modern Mechanical Engineering, 6, 51-59, (2016). http://dx.doi.org/10.4236/mme.2016.62006 .

11. Salah, G., Islam, S., Mahmoud, A. E, and Dehong, H.; "Investigation into the effect of cutting fluid concentration on the machinability of Ti-6Al-4V using vegetable oilbased cutting fluids", Journal of Engineering Technology, 6, 414-423, (2017). 
12. Bowden F.P. and Tabor D.; "The friction and lubrication of solids", Clarendon Press, Oxford - UK, (1986).

13. Czichos, H.; "Tribology: A systems Approach to the Science and Technology of Friction, Lubrication and Wear (Tribology Series 1)", Elsevier, Amsterdam (1978).

Table 1 L27 array DOE showing actual input and output variables for AKO VBCF.

\begin{tabular}{|c|c|c|c|c|c|c|}
\hline \multirow[b]{2}{*}{ Run No } & \multicolumn{3}{|c|}{ Input (Independent) Variables } & \multicolumn{3}{|c|}{ Output (Dependent) Variables } \\
\hline & $\mathrm{X}_{\mathrm{S}}, \mathbf{r p m}$ & $\mathbf{X}_{\mathrm{t}, \mathrm{min}}$ & $\mathbf{X}_{\mathbf{d}}, \mathbf{m m}$ & $\mathrm{X}_{\mathrm{ST}},{ }^{\circ} \mathrm{C}$ & $\mathrm{X}_{\mathrm{SR}, \boldsymbol{\mu m}}$ & $\mathrm{X}_{\mathrm{CT}, \mathbf{m m}}$ \\
\hline 1 & 90 & 2 & 1 & 41.0 & 3.3 & 0.20 \\
\hline 2 & 90 & 4 & 1 & 42.2 & 3.2 & 0.21 \\
\hline 3 & 90 & 6 & 1 & 43.4 & 3.1 & 0.21 \\
\hline 4 & 90 & 2 & 2 & 42.1 & 3.5 & $\mathbf{0 . 2 3}$ \\
\hline 5 & 90 & 4 & 2 & 43.5 & 3.4 & 0.24 \\
\hline 6 & 90 & 6 & 2 & 44.7 & 3.3 & $\mathbf{0 . 2 3}$ \\
\hline 7 & 90 & 2 & 3 & 43.6 & 3.7 & 0.25 \\
\hline 8 & 90 & 4 & 3 & 45.8 & 3.6 & 0.26 \\
\hline 9 & 90 & 6 & 3 & 48.3 & 3.5 & 0.26 \\
\hline 10 & 125 & 2 & 1 & 50.9 & 2.5 & 0.28 \\
\hline 11 & 125 & 4 & 1 & 52.1 & 2.4 & $\mathbf{0 . 3 0}$ \\
\hline 12 & 125 & 6 & 1 & 53.3 & 2.3 & 0.29 \\
\hline 13 & 125 & 2 & 2 & 51.7 & 2.7 & 0.31 \\
\hline 14 & 125 & 4 & 2 & 53.0 & 2.6 & 0.31 \\
\hline 15 & 125 & 6 & 2 & 55.1 & 2.5 & 0.32 \\
\hline 16 & 125 & 2 & 3 & 52.9 & 2.9 & $\mathbf{0 . 3 3}$ \\
\hline 17 & 125 & 4 & 3 & 55.4 & 2.8 & 0.34 \\
\hline 18 & 125 & 6 & 3 & 59.0 & 2.7 & $\mathbf{0 . 3 3}$ \\
\hline 19 & 160 & 2 & 1 & 61.0 & 1.7 & 0.36 \\
\hline 20 & 160 & 4 & 1 & 62.4 & 1.6 & $\begin{array}{l}0.35 \\
\end{array}$ \\
\hline 21 & 160 & 6 & 1 & 63.7 & 1.5 & 0.36 \\
\hline 22 & 160 & 2 & 2 & 62.9 & 1.8 & 0.38 \\
\hline 23 & 160 & 4 & 2 & 63.5 & 1.6 & 0.37 \\
\hline 24 & 160 & 6 & 2 & 65.1 & 1.4 & 0.38 \\
\hline 25 & 160 & 2 & 3 & $\begin{array}{l}63.8 \\
\end{array}$ & 1.9 & 0.40 \\
\hline 26 & 160 & 4 & 3 & 66.7 & 1.7 & 0.39 \\
\hline 27 & 160 & 6 & 3 & 69.2 & 1.5 & 0.40 \\
\hline
\end{tabular}

Table 2 L27 array DOE showing actual input and output variables HBCF.

\begin{tabular}{|c|c|c|c|c|c|c|}
\hline \multirow{2}{*}{ Run No } & \multicolumn{3}{|c|}{ Input (Independent) Variables } & \multicolumn{3}{|c|}{ Output (Dependent) Variables } \\
\hline & $\mathrm{X}_{\mathbf{s}}, \mathbf{r p m}$ & $X_{t}, \min$ & $\mathbf{X}_{\mathrm{d}}, \mathbf{m m}$ & $\mathbf{X}_{\mathrm{ST}},{ }^{\mathrm{o}} \mathrm{C}$ & $\mathrm{X}_{\mathrm{SR}, \boldsymbol{\mu m}}$ & $\mathbf{X}_{\mathrm{CT}}, \mathbf{m m}$ \\
\hline 1 & 90 & 2 & 1 & 45.1 & 2.4 & 0.17 \\
\hline 2 & 90 & 4 & 1 & 45.4 & 2.3 & $\mathbf{0 . 1 7}$ \\
\hline 3 & 90 & 6 & 1 & 46.1 & 2.2 & 0.18 \\
\hline 4 & 90 & 2 & 2 & 45.1 & 2.5 & 0.21 \\
\hline 5 & 90 & 4 & 2 & 46.3 & 2.3 & 0.20 \\
\hline 6 & 90 & 6 & 2 & 46.9 & 2.2 & 0.20 \\
\hline 7 & 90 & 2 & 3 & 46.3 & 2.7 & 0.23 \\
\hline 8 & 90 & 4 & 3 & 47.2 & 2.6 & 0.24 \\
\hline
\end{tabular}




\begin{tabular}{|c|c|c|c|c|c|c|}
\cline { 5 - 7 } 9 & 90 & 6 & 3 & 48.2 & 2.4 & 0.23 \\
\hline 10 & 125 & 2 & 1 & 51.1 & 1.6 & 0.26 \\
\hline 11 & 125 & 4 & 1 & 52.1 & 1.5 & 0.26 \\
\hline 12 & 125 & 6 & 1 & 52.9 & 1.4 & 0.26 \\
\hline 13 & 125 & 2 & 2 & 52.0 & 1.8 & 0.28 \\
\hline 14 & 125 & 4 & 2 & 53.0 & 1.7 & 0.28 \\
\hline 15 & 125 & 6 & 2 & 54.1 & 1.6 & 0.27 \\
\hline 16 & 125 & 2 & 3 & 52.8 & 2 & 0.29 \\
\hline 17 & 125 & 4 & 3 & 54.1 & 1.9 & 0.30 \\
\hline 18 & 125 & 6 & 3 & 54.7 & 1.8 & 0.29 \\
\hline 19 & 160 & 2 & 1 & 57.6 & 1.3 & 0.32 \\
\hline 20 & 160 & 4 & 1 & 58.4 & 1.2 & 0.31 \\
\hline 21 & 160 & 6 & 1 & 59.2 & 1.1 & 0.31 \\
\hline 22 & 160 & 2 & 2 & 57.5 & 1.4 & 0.33 \\
\hline 23 & 160 & 4 & 2 & 58.9 & 1.3 & 0.34 \\
\hline 24 & 160 & 6 & 2 & 60.3 & 1.2 & 0.33 \\
\hline 25 & 160 & 2 & 3 & 58.7 & 1.5 & 0.35 \\
\hline 26 & 160 & 4 & 3 & 61.3 & 1.3 & 0.35 \\
\hline 27 & 160 & 6 & 3 & 64.5 & 1.1 & 0.36 \\
\hline
\end{tabular}

